\title{
Thinking embodiment with genetics: epigenetics and postgenomic biology in embodied cognition and enactivism
}

\author{
Maurizio Meloni ${ }^{1}$ D Jack Reynolds ${ }^{2}$ (D
}

Received: 29 December 2019 / Accepted: 11 June 2020 / Published online: 18 June 2020

(c) The Author(s) 2020, corrected publication 2020

\begin{abstract}
The role of the body in cognition is acknowledged across a variety of disciplines, even if the precise nature and scope of that contribution remain contentious. As a result, most philosophers working on embodiment-e.g. those in embodied cognition, enactivism, and ' $4 \mathrm{e}$ ' cognition-interact with the life sciences as part of their interdisciplinary agenda. Despite this, a detailed engagement with emerging findings in epigenetics and post-genomic biology has been missing from proponents of this embodied turn. Surveying this research provides an opportunity to rethink the relationship between embodiment and genetics, and we argue that the balance of current epigenetic research favours the extension of an enactivist approach to mind and life, rather than the extended functionalist view of embodied cognition associated with Andy Clark and Mike Wheeler, which is more substrate neutral.
\end{abstract}

Keywords Enactivism · Embodied cognition · Epigenetics · Plasticity · Postgenomics $\cdot$ Memory

The role of the body in cognition is acknowledged across a variety of disciplines, even if the precise nature and scope of that contribution remains contentious. As a result, most contemporary philosophers working on embodiment-e.g. those in embodied cognition, enactivism, and ' $4 \mathrm{e}$ ' cognition-interact with the life sciences as part of their interdisciplinary agenda. Despite this, a detailed engagement with emerging findings in epigenetics and post-genomic biology has been missing from proponents of this embodied turn. Surveying this research provides an opportunity to rethink the

$凶 \quad$ Maurizio Meloni

Maurizio.meloni@deakin.edu.au

1 Alfred Deakin Institute for Citizenship and Globalization, Deakin University, Melbourne, VIC, Australia

2 Faculty of Arts and Education, Deakin University, 221 Burwood Highway, Burwood, VIC 3125, Australia 
relationship between embodiment and genetics. We argue that the balance of current epigenetic research favours an extension of the enactivist approach to mind and life, and a stronger integration of biology and cognition, rather than the extended functionalist view of embodied cognition associated with Andy Clark and Mike Wheeler, which is more substrate neutral.

Some preliminary remarks and definitions will help to set the scene for this argument. If cognition is held to be embodied in the whole organism rather than being fundamentally in the brain - as well as being extended into the physical, social, and cultural environment - then a biological account of this structural coupling at the cellular and neuronal level appears important to any such argument. At the very least, the rethinking of the orthodoxy concerning mind and cognition in "embodied mind" and "4e" approaches has obvious parallels to the way in which developmental systems theory, niche-construction, and 'evo-devo' have challenged the over-simplistic genecentrism of neo-Darwinism, as has been recognised (Thompson 2007). Rather than looking at development as the trivial activation of an internal (genetic) program, and evolution as the dualistic partition of genetic and environmental causes, these frameworks have highlighted the contingent and open-ended nature of ontogeny, the multiplicity and multidirectionality of biological information (bringing together ecological, cellular and genetic resources), the inclusive nature of inheritance, and the significance of the organism's activity in constructing its own environment (Oyama et al. 2001; Odling-Smee et al. 2003). An overarching framework, the so-called extended evolutionary synthesis, has been recently proposed to accommodate these conceptual changes in development and evolution (Laland et al. 2015). In a converging way, since the late 1990s philosophers of science like Godfrey-Smith have emphasized the importance of phenotypic plasticity to explain how the organisms' features, including cognition, can adaptively cope with mutating environments: cognition as an intelligent tracking of environments $(1998,2017)$. Given their focus on the situatedness and embeddedness of knowledge-generating mechanisms (Lyon 2017), proponents of both embodied cognition and enactivism have drawn on these frameworks, but much of the 'parallelism' has been on the critical or negative side of the story, elaborating for instance how the mind or genes don't work (Moss 2003). The positive side has remained more speculative, possibly because empirical research on the mechanisms, functions, and molecular pathways that could vindicate these claims was still nascent. It is hence arguable that claims regarding the greater biological robustness of embodied cognition and enactivism remain at least somewhat promissory, and in need of updating, notwithstanding the pioneering writings by Francisco Varela, and further insightful work by, Lyon (2006), Thompson (2007), Sheets-Johnstone (2011), and Di Paolo (2018), who have all emphasised the biological nature of cognition.

In this article, we consider what the expansion of study in molecular epigenetics over the last 15 years can bring to some recent debates in embodied cognition. Epigenetics and microbiomics are the two fastest expanding disciplines in postgenomics (a concept we shall define later), but while recent attempts have been made to consider the significance of bacteria and other microbes to expand philosophical frameworks like the environmental complexity thesis (Lyon 2017), the potential convergences between epigenetics and phenomenology of mind and cognition remain under-investigated. Coined by British developmental biologist Conrad H. Waddington in the 1940s as a 
neologism to bring together epigenesis and genetics (Van Speybroeck 2002), epigenetics is today defined as the branch of molecular biology that investigates changes to the chemical structure of DNA (chromatin) triggered by, and in response to, wider environmental influences. ${ }^{1}$ That a wider regulatory architecture, rather than just the DNA sequence, is required by evolution to generate phenotypic changes is evidenced by well-known examples where genetically identical organisms, for instance honeybees (apis mellifera), produce different adult phenotypes (sterile worker or fertile queen) by following different feeding regimens with only queen larvae fed royal jelly throughout development (Kucharski et al. 2008). The importance of the wider environmental niche in modulating gene expression is further evidenced by experimental work in epigenetics. ${ }^{2}$ While similar effects in humans can be only tracked indirectly and caution about generalization is recommended (Heard and Martienssen 2014), there is now a growing body of epidemiological studies that has shown long-term epigenetic effects of nutritional shocks (famine, war) on metabolic and cardiovascular responses up to the second generation after the exposure (Painter et al. 2008).

Importantly, recent findings also suggest that alteration in epigenetic marks are involved in neurodevelopmental disorders of cognition (Gabriele et al. 2018) and that normal epigenetic functioning subserves a number of phenomena, including associative learning, memory formation and stabilization, responsivity to stress and affective episodes, and forms of social cognition associated with mirror neurons (Fagiolini et al. 2009; Day and Sweatt 2011; Ferrari et al. 2013; Post 2016; Ginsburg and Jablonka 2018). We will address some of these studies in what follows, but for now a simple observation will suffice. Many of these same phenomena are important platforms for embodied approaches to the mind, ${ }^{3}$ yet arguments about the nature and scope of embodied cognition proceed without due attention to these details, with epigenetics either not considered or given only fleeting reference. ${ }^{4}$ But both the general arguments

\footnotetext{
1 While Waddington coined the noun epigenetics in the $1940 \mathrm{~s}$, epigenetic as the adjectival form of epigenesis has been used since the seventeenth century to describe development as a process of increasing complexity in opposition to preformationism.

2 Feeding a pregnant agouti mouse on a methyl supplemented diet alters expression of the promoter of the agouti gene. As a result, offspring are slim and brown rather than fat, prone to diabetes and yellow (Waterland and Jirtle 2003). Another suggestive area of research regards poor grooming behaviour in dams, and how this affects neurological development in pups by altering patterns of brain development. When adult, low-licked pups reproduce the inducing behaviour and thus transmit the effects of the neglect to the next generation. Given that cross-fostering pups to high licking foster dams stops this effect, this pattern of transmission is considered at least partly independent of genetic factors (Lutz and Turecki 2014).

3 For example, it is usually maintained that episodic memory and action are facilitated by bodily position and modulated through affect, and mirror neurons are central to enactivist claims regarding our capacity to directly perceive the intentional states of others, whether in regard to another person's intentionally grasping an object (e.g. a door to open, or a ball to throw) or in interacting with facial expressions of anger, fear, and disgust (Gallagher 2005).

4 There is no reference to epigenetics in Gallagher's Enactivist Interventions (2017), despite a chapter on the evolutionary aspects of the body. Menary states that his 4e "cognitive integration" theory is "fully committed to the extended synthesis... which introduces the importance of extra-genetic channels of inheritance, including ecological inheritance, epigenetic inheritance, and the role of a developmental niche in assembling phenotypic traits" (Menary 2018, p. 201). Di Paolo's chapter on life in the same handbook goes into a little more detail (2018), and there is a brief discussion in Fuchs' recent book (2018, p. 141), which views the brain as a mediating and resonance organ. In general, however, these claims are programmatic in nature, without providing details.
} 
against genocentrism, as well as arguments about the causal role of the body and any particular biology to cognition, would benefit from a detailed treatment of epigenetics to better understand the scaffolding of corporeal responsiveness to environmental triggers and cues. It is not enough to say that the mind is embodied: we need also to be able to say how (Gallagher 2005, p. 1, citing Gerald Edelman). As well as encouraging philosophers to think of the relationship with biology and naturalization in a more dynamic and generous way, a positive focus on how postgenomic biology is actually taking shape is also helpful in drawing attention to some unanticipated consequences of extended views of heredity and permeable notions of genomic functioning (Bonduriansky and Day 2019). There are increasing worries concerning somatic and environmental determinism, a different but no less pernicious form of 'strong instructionism' coming from environmental or bodily exposures rather than DNA, which is, according to some (e.g. Shapiro 2012), a potential problem for views that emphasise how the body shapes the mind (Gallagher 2005; Noë 2004). Attitudes towards this problem also appear to divide more extended functionalist approaches to embodied cognition (like that of Wheeler and Clark 2008) from some more enactivist construals (i.e. Thompson 2007), especially "autopoietic" enactivism, which is committed to some form of life-mind continuity thesis and the relevance of biology at all levels to cognition. While the conversation has moved away from the stale opposition of the biology-versus-culture construction of Neo-Darwinism's heyday, important problems remain regarding the extent to which experiences of memory, learning, and cognition are fully permeated by the details of our biological embodiment, as we will see in Sects. 3 and 4.

\section{Embodied Cognition and Enactivism}

In some usage, "embodied cognition" is the broader or umbrella term within which versions of enactivism (of which there are at least three) are situated. On that view, the relationship between embodied cognition and enactivism is something like the distinction between genus and species. Without wanting to reject that picture, in this paper we will generally use the term "embodied cognition" in a more restricted fashion, referring to views for which the body is treated as an important part of a "larger mechanism" story about cognition, rather than as making any sort of "special contribution" (Clark 2008a, b). Clark and Wheeler serve as the main representatives of this view, in what follows. Embodied cognition thus refers to views wherein cognition is multiply realisable and any particular biological flesh is not envisaged as playing a special or constitutive role. Given their roots in AI and cognitive science, they conceive of cognition as first and foremost information-processing models of the mind, and they usually do not outright reject representational and computational approaches, but rather seek to expand and complicate them. By contrast, in our use "enactivism" refers to views that are stronger in the claims they make about the connection between embodiment and cognition: in short, particular bodies matter essentially or constitutively for cognition. As a result, the biological sciences play a stronger constraining role, albeit complemented by philosophies of nature. Enactivism hence refers predominantly to what is called autopoietic enactivism, and philosophers like Varela and Thompson, 
more so than to sensori-motor enactivism (e.g. Degenaar and O'Regan 2015; Noë 2004 and others) or radical enactivism (e.g. Hutto and Myin 2013), although we expect that other versions of enactivism will be able to find common cause with at least some of our arguments. 5

Given this focus, it is appropriate to introduce enactivism through one of the more important books for the effort to rethink embodiment in a biologically plausible fashion: Varela, Thompson, and Rosch's The Embodied Mind. They drew on phenomenology in offering an account of the embodied mind in nature, albeit with the life sciences central to their effort, and with Varela (a biologist by training) advocating the idea of 'mutual constraint' between the biological sciences and philosophical treatments of the mind and cognition (Varela 1996). The Embodied Mind outlined a radical view of embodiment that was criticized by many for seeking to 'upset the apple cart' and advocating revolution in the relevant mind sciences rather than reform (Dennett 1993). Varela, Thompson and Rosch's contestation of representationalist views of the mind drew on cellular biology and molecular genetics, and in Thompson's (2007, p. 179) subsequent book, Mind in Life, this was extended to address the possibility of a more generous view of genomics not just as naked DNA. A key idea is that mind (as with cellular life in general) is essentially self-organizing and actively generates meaning, and there is a continuum between mind and life, with cognition grounded in the bio-dynamics of living systems. While autopoietic versions of enactivism have given more attention to biology than to other major forms of enactivism (i.e. 'sensorimotor' and 'radical'), even here references to epigenetics are primarily deployed as a way to expand inheritance systems rather than, as we argue, a way to think of embodiment at a deeper level as the entanglement of meaning and flesh through which corporeal sensitivity and responsiveness to the world is enabled. If we are taking embodiment seriously, 'the morphological, biological, and physiological details of an agent's body' (Newen et al. 2018, p. 5) matter for this debate.

Consider for instance standard examples of embodied cognition, which include the Tetris player's fast and timely response to slot their pieces into an 'empty' space apparently without the time to think or represent them, or the sports-player's real-time and dynamic responses to openings and opportunities on their playing field. The sort of online coping with an environment in which our body adjusts or comports itself at a motoric and pre-reflective level looks intelligent and cognitive, but without any reflective 'thinking' or obvious meta-cognition. In such cases, cognition seems to not be just in the head but 'leak' into the world, as Clark says (2008a), such that there is 'knowledge in the hands' when we play the piano, as Merleau-Ponty (2012) had earlier argued.

These examples of online coping are generally positively framed in this literature, as facilitating agency and fluid action. But our coping with the environment is not always optimal, and our capacity to cope (or not) is variable across individuals, for both biological and sociological reasons. The particular types of bodies we have, and their unique history of behavioural interactions with a given milieu and capacity

\footnotetext{
5 Hutto et al. argue that: "it would be hard to deny that cognitive processes depend on particular materials despite exhibiting varying degrees of substrate-neutrality. What is not established is that cognitive processes are maximally substrate-neutral such that it is possible to re-create all their relevant causal patterns in alternative media" (2018).
} 
of being affected by things, have an impact on coping and cognition. This is where a wider appreciation of epigenetics matters for both embodied cognition and enactivism. As the alterable mediators that enable the active coupling between organism and environment over the lifespan (Fagiolini et al. 2009; Pinel et al. 2018), epigenetic marks constitute an opportunity to re-conceptualize the 'fleshed' background of the organism's agency, particularly what stands pre-reflectively and non-thematically before cognition, orientating our body in the world (Frost in press). There is not just 'body and world' in cognition, but 'bodies and worlds', with each organism marked by distinctive biological and physiological sediments embedded in an unrepeatable history of interaction with the environment. Epigenetic mechanisms help to reveal the fundamental stratification and fine-grained scaffolding of embodied subjectivity, mostly at the level of what phenomenologists have called a 'passive synthesis'. This is the temporalized and pre-conscious experience of corporeal and affective givenness and horizonality upon which the lived experience of agency and cognition rests. In so doing, a phenomenological reading of epigenetics challenges the topography of 'body and world' at a second level, not only by pluralizing bodies and worlds, but by showing how organismic and worldly structures are dynamically and inextricably coupled (Frost in press). While some have argued that autopoietic enactivism has a risk of 'idealism', in insulating the agential capacity of the organism from its environmental embedding (De Jesus 2016), or favouring a certain asymmetry of the inside over the outside (Oyama 2011), proper attention to epigenetics stands as a corrective to this tendency. This resonates with some famous remarks from Merleau-Ponty regarding the intertwining between body and world (Meacham and Papageorgiou 2007), which he also explicates in relation to Uexküll, Waddington, and an earlier understanding of epigenetic biology in his Nature course notes (Merleau-Ponty 2003).

This epigenetic background enables and constrains how learning and socialisation happens. Previous experiences exert an affective pull (or push, if negative) towards producing a certain set of characteristics or consequences. The similarity between present affective pulls/pushes and similar previously experienced affective pulls/pushes, tends to produce characteristics in the present similar to those experienced in the past, and so on. The result of this concordance is what we commonly refer to as a tendency. However, in the embodied cognition literature that is indebted to J. J. Gibson's ecological psychology, it is referred to as an affordance presented to an organism with an affective valence, and soliciting a response.

Affordances depend on our socio-cultural history. They also stem from basic biological facts (e.g., that our hand can readily grip this mug does not depend on a particular culture), but these facts are themselves shaped by behaviour, environment, and their consequences for epigenetic molecular neurology: i.e. whether an object or action is perceived as enticing or frightening due to deficient regulation of acute stress responses, for example, as with studies concerning rats (Liu et al. 1997). Epigenetic factors are also likely to play a role in human reflections on potential future actions, or episodic memory of previous actions. In the next section, we hence review some of the key findings about epigenetics and their conceptual challenges for ideas of embodiment. We then consider a case study regarding the relevance of recent epigenetic research on memory and learning for embodied cognition (Sect. 3), and turn to 
a debate of both physical and metaphysical implications that divides proponents of embodied cognition and enactivism (Sect. 4).

\section{Postgenomics and Epigenetics: toward an enactive genome ${ }^{6}$}

'Postgenomics' is often used in a merely chronological sense to highlight all research following the completion of the Human Genome Project in 2003 or as an umbrella term for the expansion of genomic research into the functional space between DNA sequences and proteins (Richardson and Stevens 2015). However, building on a number of recent conceptualizations (Stotz 2008; Charney 2012; Meloni 2016), we use the term here in a radical sense to imply that biology has entered a 'post-normal' phase (Ravetz 1999). In this phase, a number of unforeseen complexities about genome functioning, have led to the current conceptualization of genes as fundamentally driven by environmental cues and part of a broader regulative architecture at the cellular and organismic level (West-Eberhard 2003; Griffiths and Stotz 2013; Keller 2014).

We summarize here the postgenomic reconceptualization of genome functioning along three axes: (a) spatialization, (b) temporalization, and (c) a rediscovery of the material scaffolding of the genome. Following these three directions, we argue that, compared with the formerly sequestered unit of heredity of the Neo-Darwinian synthesis, the postgenomic genome appears as 'an exquisitely sensitive' or 'responsive' mechanism (Keller 2014; Jablonka 2013), while the environment has moved from the role of passive background to being seen as 'instructive' that is, an inducer and generator of phenotypes (West-Eberhard 2003).

By spatialization we mean that in postgenomics, the direction of research has moved away from the naked DNA to a broader consideration of the overall regulatory network of the genome, a rediscovery of complexity that is a vindication of classical holistic and anti-reductionist tropes (Moore 2015). This wider architecture includes many epigenetic mechanisms that often interactively organize the regulation of gene expression: DNA methylation, modification of histone proteins, non-coding RNAs (ncRNAs), X chromosome inactivation, genetic imprinting, and nucleosome positioning (Richards 2006; Portela and Esteller 2010). DNA methylation, the moststudied epigenetic mutation, refers to the addition of a methyl group to a DNA base that inhibits gene transcription. Methylation and other epigenetic mechanisms of this extended regulatory network of DNA are involved in responding to environmental signals, which can originate in the cellular environment around the DNA or more broadly in the organism's developmental niche, including different environmental exposure and nutritional inputs. This shift in focus overturns the linear logic of biological information from DNA to the organism and looks instead at the wider distributed network within, between, and beyond the cell throughout which biological information is produced (Stotz 2006, p. 914; Griffiths and Stotz 2013; Rheinberger and Müller-Wille 2017; Stallins et al. 2018).

By temporalization we mean that genomes and their wider epigenetic architecture are no longer 'understood as the same in every cell of the body for all of that body's

\footnotetext{
${ }^{6}$ This section expands and updates on previously published work by one of us (Meloni 2016, 2019).
} 
life' (Lappé and Landecker 2015), but instead as changing across the lifespan and in different tissues of the body in response to a number of organismic inputs and environmental exposures. The view of a timeless and sequestered genetic blueprint set once for all at the beginning of life is replaced with one that is dynamically changing in critical period of developments (in utero, early life, adolescence, pregnancy, aging) (ibid.).

While examples of substantial epigenetic programming in prenatal and early post-natal periods as a consequence of exposures to stress or malnutrition are very well-known and increasingly central in Developmental Origins of Health and Disease (DOHaD), adolescence has been gaining a growing recognition as a key age for the heightened impact of epigenetic patterning on brain maturation (Mychasiuk and Metz 2016). Aging is also increasingly understood as producing changes in epigenetic patterns, mostly genome-wide demethylation, which significantly impact on the control of gene expression (Bollati et al. 2009; Pal and Tyler 2016).

The third characteristics of postgenomics is the rediscovery of the materiality of the genome. In the mainstream literature, epigenetics is usually defined in the negative as 'heritability without DNA', that is, 'the study of changes in gene function (...) that do not entail a change in the sequence of DNA' (Armstrong 2014, our italics). This standard use of a negative definition indicates, in our view, an incapacity of the present scientific language to fully capture what is at stake with a shift in focus from DNA sequence to its wider ecological embedding. We believe that a more positive understanding of epigenetics is only possible by eschewing the centrality of DNA and the informational language in which the DNA map, code or blueprint has been constructed since 1950s (Kay 2000). Rather than thinking of epigenetics as the 'fifth letter' of an otherwise linear genetic code, it is possible to look at epigenetics as the ongoing remodeling of chromatin - the 'highly dynamic' complex of nucleic acid and proteins into which DNA strings are tightly folded (Dekker et al. 2013; Atlasi and Stunnenberg 2017). A tension between an informational (and hence disembodied) and a chemical or material conception of the gene has always been part of the long history of genetic research (Griffiths and Neumann-Held 1999) but this friction may have reached an interesting tipping point. As historian Barry Barnes and philosopher John Dupré (2008, p. 105) write:

The dominant view of genomes is that they are objects made of DNA. But the actual material objects we encounter in the cell nucleus are made of chromatin, not DNA. In chromatin, DNA exists in association with various other substances including small RNA molecules and proteins, and in particularly close association with the histone proteins that provide something like a spool around which the DNA strands are coiled, and which thus facilitate the packing of DNA into the restricted space available in the cell nucleus.

Chromatin research largely precedes postgenomics but has currently found a true rebirth through epigenetics (Deichmann 2015). Given that DNA is structurally and topologically constrained by chromatin architecture (spatialization) and this architecture is constantly remodelled at a critical time of cellular development (temporalization), it is feasible to suggest that it is through these shifts in chromatin architecture that biological meaning is produced (Tark-Dame et al. 2011; Cortini et al. 2016). Chro- 
matin strands give the genome a body that can be transcriptionally 'open,' and thus potentially expressed, or 'closed,' and thus silenced by wider cellular and extra-cellular signals. The flexible rearrangement of chromatin structures enables the dynamic interplay between gene functions and the environment, and, more broadly, organism and milieu over the lifespan. Remarkably, and unlike DNA sequence, chromatin condensation is not an on/off phenomenon, but something that enables different states to be implemented as a consequence (also) of subtle cellular and environmental influences. It is this analogical property of chromatin states (rather than digital replication of information, as in DNA) that makes this macromolecule a likely candidate for the genomic embodiment and registering of the physical imprints of dynamic environmental and developmental cues that result in stable cellular and phenotypic changes (Margueron and Reinberg 2010, p. 285). Here also the analogy with debates in situated and embodied cognition is persuasive: it is the reliance on the external scaffolding of the DNA sequence that enables the genetic program to acquire biological significance (Griffiths and Stotz 2000). Chromatin may be seen as the first material scaffolding of naked DNA and a flexible mediator that enables communication with the wider network of genomic functioning, that is, its ecological embedding within, among, and outside the cell up to the whole organism (Meloni 2018).

Spatialization, temporalization and a full rediscovery of the material and morphological density of the genome are crucial to the discontinuity between genomics and postgenomics. It is this difference that constitutes a significant opportunity to re-conceptualize embodiment in a way that includes rather than rejects genetics factors. The importance of this move for philosophers cannot be overestimated. Under a strictly genetic view of life, the body was turned into a biophysical abstraction or just an empty vessel for replication of the immortal germplasm (Gudding 1996). Both Mendelian and molecular genetics have proposed a stratigraphic model in which biological subunits (genes) were deemed to control superficial traits. This has led to considering the body not only as a dependent entity but often a superfluous one, creating a gap between research in genetics and ideas of embodiment. Relegated to the passive end of the genetic chain of information, this biological fragility of the body was obviously far from appealing to philosophers looking for biological correlatives of ideas of embodiment. In bridging the gulf between genotype and phenotype (Hallgrímsson and Hall 2011), epigenetics considers environmental and somatic cues as key to genomic expression. The bodily level is again made central and given an (en)active role, as the lived phenomenology (food we consume, stress and other experiences we undergo, etc.) is no longer irrelevant to genetic functioning, but a causal source of gene regulation and expression that makes every biological process socially patterned (Landecker and Panofsky 2013). With epigenetics also emerges the possibility of a scientific-friendly phenomenology, in which philosophy can risk a genuine engagement with genetics. Genetic information is no longer contained in the inert nucleotide sequence, but is driven by changes in the wider architecture of DNA that reflect the dynamic engagement between bodies and their unique cellular and extra-cellular surroundings. Bodies are sensitive to the point that even their supposed irreducible kernel of identity, DNA, is constantly reshaped in its functional expression by a multitude of environmental triggers. There is something akin to a phenomenologization of the once timeless and static DNA. Previously abstracted and neatly separated from its Umwelt, 
DNA is now an extended-DNA, as well as a DNA-in-time and in-place, oriented toward and inseparable from the pulls and pushes of its ecological embedding (via its regulative factors, methylation, acetylation, histone modifications, and non-coding RNA transcription).

This brings to light the anticipated attention of each organism to its pre-history that orient bodies to higher or lower sensitivity to certain experiences (Frost in press). Biological sense-making is not the unfolding of a pre-existing and independent program but an emergent property resulting from the enactment of bodies and world on the basis of the situated and biologically guided history of each organism (their being plugged-in with Noë), which in turn transforms the organism's milieu into a place of special epigenetic salience (expanding on Thompson and Stapleton 2009). Epigenetic studies are increasingly showing environmental triggers frame, at a lower mechanistic level, an ongoing responsiveness to early life or possible intergenerational events. This 'directionality' and discerning capacity of the perceiving body (Merleau-Ponty 2012; Todes 2001; Hoel and Carusi 2018; Frost in press) is evidenced by an emerging body of scholarship that shows how epigenetic changes not only mediate early-life experiences into long-term gene changes but also, in a few cases, into behavioural changes in later generations (reviewed in Moore 2015; Meloni 2016, 2019). The body is always embedded in developmental trajectories (Jablonka 2017), sensitized at each moment by a number of biological memories acquired at critical windows of development, and hence always 'experience-expectant'. These accumulated biological memories in an individual's own upbringing enrich phenomenological notions regarding the body-schema (Merleau-Ponty 2012), along with the idea of prenoetic constraints on perceptual experience 'as a form of world-involving intentionality that modulates (minimally) bodily behaviour without necessarily possessing informational value of any kind' (Bower and Gallagher 2013). They appear to play an important and non-linear role in the modification of gene expression, where even small changes in epigenetic patterns may impact significantly on physiological and neurodevelopmental outcomes. Biological plasticity is a complex phenomenon in which the current state of the system is always 'guided', dependent on its accumulated history (Steffen and Ringrose 2014).

Epigenetics is a placeholder for this emerging plasticity. While it also opens obvious bridges to alternative views of inherent excitability, agency and meaning in biological flesh (Riskin 2016; Frost in press), in the section that follows we look at the potential engagement with some of these ideas on themes acknowledged to be vital to the ' $4 \mathrm{e}$ ' (embodied, embedded, enactive, and extended) case-memory and learning. We then consider in Sect. 4 a 'divide' between proponents of embodied cognition and enactivism concerning the ultimate significance of embodied responsiveness.

\section{Memory and learning: an epigenetic revisitation}

We have argued that epigenetics is significant for many phenomena of interest to proponents of both embodied cognition and enactivism, and we have outlined some of the conceptual revisions it heralds. Thus far, however, we have made the case at a general level. It is useful to consider a more concrete case study-memory and learning - to 
show how epigenetic research ramifies on the debates we have introduced, which have both a metaphysical and a physical-scientific dimension. Memory and learning are significant aspects of cognition, arguably indispensable for all animals who possess associative learning capabilities (Piersma and van Gils 2011). Animals with associative learning capabilities can adapt to a changing environment because they possess some kind of memory (perhaps procedural rather than episodic) ${ }^{7}$ of previous rewards and punishments, previous traumas and hunger, with key events and any associated learning 'in the wild' likely to be primarily oriented around evolutionary biology's famous 4Fs: fighting, fleeing, feeding and fornicating. This capability is subtended by various factors. In particular, epigenetic mechanisms are crucially involved, specifically by consolidating previous experiences intro traces or engrams, with exactly how this works a focus of ongoing research (see Kim and Kaang 2017; Williams and Kyrke-Smith 2018; Bédécarrats et al. 2018).

And, of course, memory and wider learning processes are vital to all debates on epigenetics. Epigenetics was traditionally conceived by Waddington as a form of cellular memory that allows the cell after division to maintain and transmit a stable phenotype to daughter cells (Jablonka and Lamb 2014). Epigenetic mechanisms, whether methylation, acetylation or chromatin rearrangement, are also often rendered through the image of a cellular memory (Jeppesen 1997; Nicol-Benoit et al. 2013). In animal studies, some of the most-cited epigenetic research focuses on the transmission of memories (olfactory, traumatic) across generations, for instance in rats (Dias and Ressler 2014; Gapp et al. 2014; Kim and Kaang 2017). At a lower mechanistic level, an increasing number of studies are expanding on Kandel and colleagues' seminal work on the importance of chromatin structure alteration (which today we would call epigenetic regulation) for memory storage and enabling long-term-memory-related synaptic plasticity (Guan et al. 2002). While Kandel's article cautiously raised the problem of whether it was the whole cell or some compartmentalized gene product that stores memory, and highlighted the importance of looking at a bi-directional regulation of plasticity, other contemporary research (in both Aplysia and C.elegans) has been less sophisticated, claiming that a simple epigenetic factor (for instance RNA rather than DNA) 'contains' memory and hence, memories can be transferred from trained to untrained animals by just transferring RNA (Bédécarrats et al. 2018; Posner et al. 2019).

How does this bear on memory and learning in philosophy of mind and cognition? This is rarely directly addressed, but we think it should be. After all, memory and adaptive learning have always been an important explanandum for any empirically oriented philosophy of mind. Even for classical representationalism, the sophisticated memory characteristic of intelligent species depends on being able to retrieve information or representational content (Sterelny 1990, p. 19), and it is this that stops us from behaving in repetitive and mechanistic ways akin to the Sphex wasp. While the famous story of the Sphex told by Daniel Dennett and others is at least partly apocryphal, being challenged by the details of the actual experiments (Keijzer 2013), a wasp will (sometimes) bring a paralysed cricket to a burrow, inspect the burrow and

\footnotetext{
7 The existence or otherwise of episodic memory - that is: recall from a first-person perspective of the experiencing of an event-is more conjectural (Ginsburg and Jablonka 2018).
} 
repeat this behaviour up to 40 times, if a human intervention (in laboratory conditions rather than a natural ecological habitat) secretly moves the cricket a few inches away while the wasp is occupied with inspecting their burrow. The wasp's problem, as the representationalist portrays it, is that they have not been able to extract the information/representational content and are thus rigidly responsive to the stimulus.

Today, there is ongoing debate over whether biological memory in humans is in fact about retrieving 'informational content', or whether learning/memory is less about content but rather the 'structure of content' (the shape, say); more like an embodied coping with epigenetic markers and environmental influence, such that episodic memory may be evoked by postural similarity to a previous incident, the sorts of case studies commonly invoked by theorists of embodied cognition and enactivism (e.g. Morris 2010; Kiverstein 2012). If that is so, this may offer reasons why representational-computational AI systems, notwithstanding their significant advances, might not yet be as flexible and adaptable in their learning as humans and higher vertebrates. Although contemporary AI systems are often not oriented around formal symbol manipulations, nor a CPU and a series of off/on 'switches', it remains difficult to comprehend how one might embed sedimented experience epigenetically into such systems, whether functionally, or perhaps even in cellular-like material, notwithstanding so-called evolutionary robotics and the work on transferrable RNA referred to above (Bédécarrats et al. 2018; Posner et al. 2019).

Properly justifying that claim about contemporary AI would take another paper, but we can grasp the significance of epigenetics for memory and learning in other ways, including by considering research around memory and the 'extended mind', which is one of the key platforms supporting the extended functionalist treatment of embodied cognition. As the name suggests, this view extended (but did not radically challenge) the representational story about cognition and memory, focusing on functions, rather than material realisers, in a similar fashion. In Clark and Chalmers' (1998) famous telling, although Otto has lost has biological memory he is nonetheless able to reliably use a notebook to find his way to an art gallery in New York. Clark and Chalmers argue that we should conclude that the notebook is a part of Otto's cognitive system in this case, at least if it serves the same function and has the same sort of reliability and access as is involved in 'normal' brain-bound memory that facilitates many other New Yorkers getting to the gallery. Without being able to address all of the details of this argument and the various critical replies, it is important to note that biological memory is still understood as a process that involves the storing and retrieving of informational content, where this content is 'sitting somewhere in memory waiting to be accessed' (Clark and Chalmers 1998, p. 12).

But this view is coming under criticism from enactivist construals that give our particular bodies, and their particular biology, a more crucial role, albeit without yet bringing epigenetics fully into the debate in the manner we propose. Anco Peeters and Miguel Segundo-Ortin (2019) nicely summarise the empirical and philosophical concerns with this understanding of memory. As they put it:

... there are two flaws with the current functionalist explanation. First, though it putatively captures the role the environment plays in the process of encoding and retrieving information, it neglects to explain why the role of bodily movement in 
both learning and recall phase (...) is of importance. Second, it is unclear how, on this account, the extra information the memory palace would presumably require being processed during the recall phase, actually helps with remembering.

We cannot follow Peeters and Segundo-Ortin and consider the details of the memory palace, an old spatial aide to remembering, in which one walks through a memory space (say a hall with doors leading to each of the great philosophers in history) to improve recall and thus enable an individual to give a philosophy talk that appears to be extemporaneous. However, they are also interested in referring to Clark's distinction between two views of embodiment, which Clark (2008a, b) calls the larger mechanism and special contribution (SC in the quote following) accounts, which we briefly introduced in Sect. 1. But, pace Clark, they aim to defend the latter rather than the former. Peeters and Segundo-Ortin $(2019$, p. 6) note:

... as the name implies, those who adhere to SC advocate that at least some of the contributions the body makes are not reducible to mere informational processes. The implication is that some of an organism's cognitive processes are shaped by the specific features of its body in a way that does not lend itself to an explanation in terms of information-processing. Shapiro specifies that there are at least two ways in which the body may influence cognition: 'first, it might generate associations that determine certain cognitive proclivities; second, the body might, via activation of motor plans, facilitate or inhibit various cognitive processes'. Thus, on SC, for the understanding of at least some cognitive processes the consideration of the role of the body is required...

Examples given include that right-handers prefer to interact with objects on their right side (Shapiro 2019), but it is arguably much more pervasive than this, drawing on the sorts of insights that have motivated both enactivism and embodied cognition, as well as Merleau-Ponty's (2012) phenomenology of embodiment before that. There is an embodied knowledge that is usually presupposed as the background for our worldly interactions, but we can also become more attentive to it, perhaps especially when this bodily 'attunement' is not present and/or failing us. One of the authors of this paper was recently endeavouring (but failing) to set up a video-conference through a computer and other devices in a university lecture theatre. It was only once he sat down in the chair, rather than standing above it, with the keyboard and other relevant devices in their places and providing relevant affordances for action (indexed to the body as a 'zero point' for action), that he was able to successfully perform the task. Embodied and procedural memory helped to facilitate the completion of a (relatively simple) task that he had been unable to perform when physically situated in an unusual or non-optimal position for such tasks, in a moderately stressful environment (i.e. hosting a visiting speaker). This is an example of how the world might scaffold our online cognising and intelligent behaviour. It is perhaps not controversial in itself, but whether or not we should view particular biological bodies as making a special (or functionally irreplaceable) contribution is. Prima facie, however, the prior experiences of an individual (and/or their ancestors) make a world of difference to even mundane experiences like this, an insight that has some epigenetic support as we will see. 
To advance the case for a special role of embodiment, Peeters and Segundo-Ortin (2019) discuss research concerning the use of a memory palace in detail. Others draw on the role of the external environment in facilitating memory in Alzheimer's patients: if placed in 1950s style accommodation, the memories and cognitive capacities of some elderly Alzheimer's patients can be restored through this changed external environment (Heersmink 2017). Sutton and Williamson (2014) appear to show that cognitive and memory activities learnt while under water are better recalled later when actually under water, and that related cognitive activities learnt on dry land are likewise better recalled on land (Godden and Baddeley 1975; Sutton and Williamson 2014). This is not just about embodied know-how for a given task to be completed under water or on dry land, but it also pertains to other cognitive tasks not directly related to particular motor-routines.

We find this account convincing, but what is it about our particular biologies that might have a special role and significance here? What is the best explanation for such capacities, and the difficulty of adequately explaining them on informationprocessing, functionalist, or computationalist treatments? Without being able to settle this, it appears plausible that those specific features of our biological bodies are less to do with representations or 'content', or something that might be designated as 'off' or 'on', but rather epigenetic markers that exert a 'push' and 'pull' on the exposure to, and consolidation of, memories (including content-rich episodic memories) and therefore learning. Exactly how might this sort of thing happen? Neuro-epigenetic research suggests that cellular and molecular changes appear to allow the formation of memory traces in response to associative learning experiences and/or non-associative and novel experiences, especially when traumatic. In other words, epigenetic mechanisms facilitate the acquisition of representational content to use more cognitivist language, or they enable us to enact or re-imagine previous experiences if we prefer enactivist construals of memory with Peeters and Segundo-Ortin (2019).

In this vein, Ginsburg and Jablonka discuss some reasons for thinking that 'synapses do not store memories but rather express memories that are stored intracellularly, in epigenetic marks' (our italics 2018, p. 316). More particularly, they point to four major types of epigenetic mechanisms that 'underlie cell memory in all types of cells, including neurons' - self-sustaining loops, structural templating, chromatin marking, RNA-mediated systems. In their account of memory retention, it is these mechanisms that enable physical traces to:

persist even when original stimulus is no longer present, and the response is no longer manifest. A latent memory trace, an engram, is formed following one or more phases of consolidation. The engram can be described at several levels of organisation, beginning with the epigenetic cellular level. It can, for example, be an epigenetic pattern in the chromatin of the nucleus of a single cell or induced regulatory RNA molecules and protein complexes that not only change the threshold of the reaction of the cell to the inducing stimulus but can also be transferred between cells. (Ginsburg and Jablonka 2018, p. 229)

Other epigenetic scientists reach related conclusions. In a review article, Zovkic et al. (2013, p. 61) argue: 
In the last decade, epigenetic markers like DNA methylation and posttranslational modifications of histone tails have emerged as important regulators of the memory process. Their ability to regulate gene transcription dynamically in response to neuronal activation supports the consolidation of long-term memory.

In this respect, of course, the most famous epigenetic studies concern fear memory and how this is consolidated and perhaps passed through generations in cellular material extraneous to DNA. As Zovkic et al. (2013, p. 61) put it: 'transient epigenetic modifications mediate memory consolidation by regulating gene expression within the first few hours after learning, whereas sustained changes in epigenetic modifications in cortical brain regions underlie memory maintenance over prolonged periods of time'. As such, they enable habits and pre-reflective responses to specific stimuli in the environment and associative learning. But Zovkic et al. also argue that related phenomena are found in non-associative learning, deriving from exposure to novel environments and trauma. Summing up their review, they contend: 'Ultimately, these findings point to a bidirectional relationship between epigenetic mechanisms and learning and memory, whereby learning induces the formation of novel epigenetic marks and pre-existing levels of epigenetic marks regulate the threshold for learning and memory' (our italics, Zovkic et al. 2013, p. 68). Without ruling out the capacity of a "larger mechanism" treatment of embodiment to adequately explain this bi-directional relationship, the challenge is acute, since the balance of recent epigenetic research on memory and learning appears to show that experience is strongly permeated by the details of our biological embodiment, pace Clark (2008b, p. 53).

\section{Embodied Cognition versus Enactivism: A postgenomic and epigenetic argument?}

We have suggested that postgenomics in general, and epigenetics in particular, provide resources for a 'dynamic materialism' that is of direct relevance to embodied cognition and enactivism, even if these interdisciplinary fields have said relatively little about the positive details of epigenetic research thus far. We have shown in the previous section how this research matters for these fields, specifically in relation to memory and learning. However, there is another reason for thinking more deeply about epigenetics, and that is because there is an implicit debate about the significance of the post-genomic and epi-genetic between major advocates of embodied cognition and enactivism respectively. We introduced this debate in the previous section, but further consideration of epigenetics is crucial in order to weigh the options for partisans of the 'embodied turn' and ascertain just how radical we might want to be regarding the integration of biology and cognition.

To begin with embodied cognition, Wheeler and Clark (2008) have posed some obstacles to any overly liberal construal of the role and significance of epigenetics and postgenomics more broadly. While Clark used the 'parity principle' and his version of functionalism to extend the boundaries of the mind into Otto's physical notebook (Clark and Chalmers 1998), in other work he and Wheeler have expressed concerns 
about the threat posed by too permissive an account of explanatory spread, including if the account of inheritance becomes too 'liberal'. Here they are not alone. It remains contested whether epigenetics has an impact on natural population dynamics and, if it does not, then some would question its broader relevance for evolutionary theory per se (cf. Baedke 2018 for discussion). But what is explanatory spread, exactly? They frame it as follows:

... one would have explanatory spread where one discovered a distributed developmental system in which non-genetic organismic and/or wider environmental factors made explanatorily non-negligible contributions to phenotypic form. That is the general picture on offer from approaches that emphasize cultural evolution, cognitive niche construction and (we can now add) emergent modularity (Wheeler and Clark 2008, p. 3570).

While Wheeler and Clark think that nothing is wrong with explanatory spread per se, they caution against throwing the explanatory baby out with the bathwater. And it is Maturana and Varela who they accuse of wrongly taking explanatory spread (where non-genetic factors make a non-negligible contribution) to overturn genocentrism, as well as to reject modularism about the brain more generally. ${ }^{8}$ In their view, we can keep non-trivial explanatory spread, of the sort emphasised by Maturana and Varela (and 'evo-devo', DST, etc.), without diminishing the focus on the genome (and DNA) as playing the fundamental causal role. Maturana and Varela, by contrast, have a holistic focus that promises (or threatens, depending on one's perspective) to overturn the Modern Synthesis, as well as mechanistic and modular explanation more generally. Here is how Maturana and Varela frame their general point in The Tree of Knowledge:

We have often heard it said that genes contain the 'information' that specifies a living being... [but] when we say that DNA contains what is necessary to specify a living being, we divest these components of their interrelation with the rest of the network. It is the network of interactions in its entirety that constitutes and specifies the characteristics of a particular cell, and not one of its components (Maturana and Varela 1987, p. 69).

Although this book and these remarks come from before turn-of-the-century discussions about postgenomics and epigenetics (and before Varela's own more explicitly enactivist period), Maturana and Varela's view anticipates some key platforms of autopoeietic enactivism. In this case, they contend that if the environment and other factors play a significant causal role, or if DNA is much more dependent on extragenetic factors than has been standardly held, we should take a wider view focused on the cell as a whole, and indeed the whole embodied organism. We might subsequently understand distinctions between the genome and epigenome, genotype and phenotype, etc., in that light.

But Wheeler and Clark contend that Maturana and Varela's argument depends on a picture of genes as information carriers, as coding for traits in a specific way they call 'strong instructionism'. Strong instructionism is:

\footnotetext{
8 In brief, modularity involves subsystems in the brain or body that are relatively discrete, and able to adequately explain some higher-level capacity or function, a typical model of mechanistic explanation.
} 
the claim that what it means for some element to code for an outcome is for that element to fully specify the distinctive features of that outcome, where 'full specification' requires that those distinctive features may be predicted purely on the basis of what may be known about the putatively coding factor... to fully specify the form of that trait. (Wheeler and Clark 2008, p. 3571)

Differently put, it is the idea that the 'genotype as a whole should be conceived as a set of instructions for, a blueprint for, a plan for, a specification of, or a program for, the building of the phenotype' (Wheeler 2007). While it is possible to consider postgenomics as expanding the set of instructions (e.g. DNA plus a further set of instructions), it is also possible to consider them as embracing a more complex understanding of causality that is not so mechanistic (c.f. Baedke 2018, p. 10). But to return to the debate at issue, is all 'coding' talk about genes tied to strong instructionism? Wheeler and Clark think not. As such, they accuse Maturana and Varela of a straw man argument, of 'a spectre without much of a haunting pedigree'.

Elsewhere, Wheeler gives more details. While noting that we might contend that genes code for traits because they 'set certain parameters for the developmental systems that generate phenotypes', he argues we end up back at the same problem of excessive liberality in our causal picture, violating 'our old friend the weakened uniqueness constraint' (Wheeler 2007). In his view, too much seems to be counted as coding for the phenotype. But what is too much exactly? Here views differ, however, and we have seen that recent epigenetic research indicates a more pervasive explanatory spread than Wheeler and Clark were inclined to accept in the mid 2000s. ${ }^{9}$

Indeed, in the final pages of his book, Supersizing the Mind, Clark (2008a) draws on Richard Dawkins, whose work had been sympathetically engaged with by Clark's teacher, Dennett. In particular, Clark draws on the idea that the spider's body spins and maintains the web that then constitutes part of its extended phenotype:

Through this special lens, the spider's web appears as a proper part of the spider's extended phenotype, and the organism emerges as no more (and no less) than an adaptively potent non-random concentration of DNA. This perspective, Dawkins suggests, is not compulsory nor can it be simply proved or disproved by experiment. (Clark 2008a, p. 218, cf. p. 123).

This is an interesting analogy for Clark to conclude his book with, comparing his own account of embodied cognition with Dawkins' influential statement of a DNA-centric view, wherein the body is but a vessel, a carrier of information: precisely the view that our account of epigenetic research in Sect. 2 challenges. Now, exactly how committed Clark himself is to Dawkins' view of DNA is not completely clear, but he draws attention to the idea of a 'mental flip' whose virtue lies 'in the different ways of seeing familiar phenomena', inviting 'us to view the larger organism-environment system in a new and illuminating light' (Clark 2008a, p. 218). But does Clark's own 'flip', and

\footnotetext{
9 That said, we also think what we have outlined here provides the beginnings of an answer to a problem that Wheeler raises but leaves unanswered in his important book, Reconstructing the Cognitive World. Without mentioning epigenetics, he discusses the need for a subagential account of Heideggerian "thrownness" and glosses it in ways that gel with the picture offered here, and hence appear to push him closer to enactivism (Wheeler 2005, p. 277).
} 
his own construal of embodiment (larger mechanism rather than special contribution) view the organism-environment system in a related way to Dawkins: that is, as part of a story involving many complex mechanisms, while retaining a distinction between the information-centric aspect that is causally efficacious (the DNA) and other parts of the cells and broader environment that are involved in a weak causal sense but are not constitutively relevant? Clark appears commited to this view when he explicitly argues that experience is not non-trivially permeated by the details of biological embodiment (Clark 2008b, p. 53, cf. also Clark 2008a, p. 205). Maintaining such a view, however, depends on a conservative rather than radical reading of epigenetics of the sort we have outlined here, and wherein experience (including memory and learning) is permeated by biological embodiment. As Baedke puts it: 'To back up the idea that genes are more important causal factors for traits than epigenetic regulatory factors, one has to show that genes have a unique ontological or epistemic status compared to the epigenetic factors' (Baedke 2018, p. 112). Who has the burden of proof here? What verdict did Clark himself reach? His view of both cognition and genetics appears to want to hang on to some key parts of the work of Dennett, and perhaps even Dawkins, for whom the organism was famously no more or less than the non-random concentration of DNA. And while it is true that some of the more radical readings of epigenetics will no doubt be found to be overstatements, we think that the balance of research concerning memory and learning discussed by Peeters and Segundo-Ortin (2019), and the material substratum for this (epigenetics), suggests that the enactivist treatment of embodiment might be the better overarching view of mind and life.

\section{Conclusion. Thinking embodiment with (epi)genetics: opportunity and caveats}

In this paper, we have argued that greater engagement with postgenomic science is required for proponents of both embodied cognition and enactivism to justify their self-proclaimed biological sensitivity. Alongside other emerging disciplines like microbiomics (Lyon 2017), epigenetics represents an opportunity but also a challenge and a task. Favouring a charitable reading of epigenetics, we have focused on its potential to meaningfully constrain philosophical and psychological theorizing. However, we are not blind to some of the awkward aspects of this research. Leaving aside the hype and risk of prematurely accepting findings that are still contested, there is a risk of reductionist naturalism in epigenetics, and hence a need to consider the phenomenology of lived experience that it permeates, albeit in a way that has been recognized as 'bi-directional' (Zovkic et al. 2013). This attention to experience remains what Evan Thompson calls the 'red thread' in enactivism (2007). However, it is often given little elaboration in many of the current sciences of epigenetics, where the interaction of body and world is still often rendered through (passive) metaphors of impression and imprint (Meloni 2019), rather than a more enactive account of biological agency and sense-making (Frost in press). One example is animal models in research on memory and neuroepigenetics that tend to discard the body in favour of a simplistic view of physical substrates of memory. This is obviously in tension with more phenomenological views of memory as the result of a 'network of interaction', as in Maturana 
and Varela, and amplified nicely in regard to memory by Peeters and Segundo-Ortin (2019). It is at this level that epigenetics needs philosophy. Opening up a space for dialogue is timely and urgent, given the exponential growth and topic expansion of publications in epigenetics (from mental health to behavioural effects of toxins) and the nascent state of many of its epistemological and methodological concepts.

Besides the importance of direct philosophical criticism, a closer engagement of philosophy with epigenetics appears significant to deciding some central debates between partisans of the embodied turn, between more and less radical positions concerning both cognition and the Modern Synthesis. Enactivists are more radical regarding biology and the reception of Darwin, but proponents of embodied cognition, such as Clark and Wheeler, are more ready to situate accounts of cognition within, rather than against, a Darwinian theoretical biology. In our view the balance of evidence coming from research in epigenetics, especially on memory and learning, favours a stronger view than Clark's 'larger mechanism' account of embodied cognition. Resolving this more definitively will require philosophers and epigeneticists to work together, along with theoretical biologists. Does epigenetics support a version of what we might call extended instructionism (even extended computationalism)? Or does it support a view of embodied agency that emphasises causal material that is not readily codeable or computationalised, a view of embodied cognition and perception, of learning and motility, that grants the whole embodied organism a constitutive and irreducible role? Similar questions arise from the growing importance of research in chromatin. The rediscovery of the material density of the genome, and attention to its plastic and interactive scaffolding, presents an opportunity to reconsider the digital language of information genomics and the dominance of mechanistic and cybernetic explanatory models in biology. This is not to mdeny of course that other uses of epigenetics may reinforce a digitalization of the environment that flattens ontological differences between worldly things (food, historical events, chemicals) now just turned into different signals for genome functioning (Landecker 2016).

We haven't settled these debates here, since the work in epigenetics has generally not directly grappled with these sorts of questions, and how to interpret the findings remains open, to at least some extent. In this respect there is perhaps an analogy to be drawn with the burgeoning work on mirror neurons around the turn of the century, and the way they have been used to support various different philosophical and psychological positions regarding social cognition (variously: Theory Theory, Simulation Theory, hybrid, interactionist, etc.—-see Gallagher 2005; Reynolds 2018). As these debates show, with the benefit of hindsight, it is not the case that any one physical-causal story can alone establish or refute philosophical views that will also be metaphysical. Without sitting on the fence, however, we think the balance of epigenetic research suggests that a more radical interpretation of embodiment and its implications for the Modern Synthesis is called for. Here we converge on the extension of meaningmaking to epigenetic molecular processes and the notion of an 'attentive body' of social theorist Sam Frost, in which she claims that epigenetics has the potential to challenge 'the association of the fleshiness of bodies with the unintelligent and the imperceptive', and imbue the living body with an epigenetically driven 'poised responsiveness' (Frost in press). Since epigenetic marks are not directly the control of the nervous system, they move attentiveness and intentionality well beyond the cognitive system (extended 
body), thereby bringing back materiality and cognition in a stronger sense that is more characteristic of enactivist approaches to cognition and biology than the views of their more functionalist fellow travellers in embodied cognition. If philosophers as part of their interdisciplinary agenda want today to reconsider the chasm of matter and meaning, cellular processes and sense-making, we believe epigenetics offers an important candidate for such a task, something that is good to think with.

Acknowledgements We would like to acknowledge Anco Peeters and Jan Baedke for feedback on this paper, as well as the reviewers from Synthese. Jenny Lucy at ADI (Deakin University) helped make the text more readable. Maurizio Meloni's work is supported by an Australian Research Council Future Fellowship (FT180100240).

Open Access This article is licensed under a Creative Commons Attribution 4.0 International License, which permits use, sharing, adaptation, distribution and reproduction in any medium or format, as long as you give appropriate credit to the original author(s) and the source, provide a link to the Creative Commons licence, and indicate if changes were made. The images or other third party material in this article are included in the article's Creative Commons licence, unless indicated otherwise in a credit line to the material. If material is not included in the article's Creative Commons licence and your intended use is not permitted by statutory regulation or exceeds the permitted use, you will need to obtain permission directly from the copyright holder. To view a copy of this licence, visit http://creativecommons.org/licenses/by/4.0/.

\section{References}

Armstrong, L. (2014). Epigenetics. London: Garland Science.

Atlasi, Y., \& Stunnenberg, H. G. (2017). The interplay of epigenetic marks during stem cell differentiation and development. Nature Reviews Genetics, 18(11), 643.

Baedke, J. (2018). Above the gene, beyond biology: Toward a philosophy of epigenetics. Pittsburgh: University of Pittsburgh Press.

Barnes, B., \& Dupré, J. (2008). Genomes and what to make of them. Chicago: University of Chicago Press.

Bédécarrats, A., Chen, S., Pearce, K., Cai, D., \& Glanzman, D. L. (2018). RNA from trained Aplysia can induce an epigenetic engram for long-term sensitization in untrained Aplysia. eNeuro, 5(3), 1-11.

Bollati, V., Schwartz, J., Wright, R., Litonjua, A., Tarantini, L., Suh, H., et al. (2009). Decline in genomic DNA methylation through aging in a cohort of elderly subjects. Mechanisms of Ageing and Development, 130(4), 234-239. https://doi.org/10.1016/j.mad.2008.12.003.

Bonduriansky, R., \& Day, T. (2019). Extended heredity: A new understanding of inheritance and evolution. Princeton: Princeton University Press.

Bower, M., \& Gallagher, S. (2013). Bodily affects as prenoetic elements in enactive perception. Phenomenology and Mind, 4(1), 78-93.

Charney, E. (2012). Behavior genetics and postgenomics. Behavioral and Brain Sciences, 35(5), 331-358.

Clark, A. (2008a). Supersizing the mind. Oxford: Oxford University Press.

Clark, A. (2008b). Pressing the flesh: A tension in the study of the embodied/embedded mind. Philosophy and Phenomenological Research, 76(1), 37-59.

Clark, A., \& Chalmers, D. (1998). The extended mind. Analysis, 58, 7-19.

Cortini, R., Barbi, M., Caré, B. R., Lavelle, C., Lesne, A., Mozziconacci, J., et al. (2016). The physics of epigenetics. Reviews of Modern Physics, 88(2), 025002.

Day, D., \& Sweatt, J. (2011). Cognitive neuroepigenetics: A role for epigenetic mechanisms in learning and memory. Neurobiology of Learning and Memory, 96, 2-12. https://doi.org/10.1016/j.nlm.2010.1 2.008 .

De Jesus, P. (2016). From enactive phenomenology to biosemiotic enactivism. Adaptive Behavior, 24(2), $130-146$.

Degenaar, J., \& O'Regan, K. (2015). Sensorimotor theory and enactivism. Topoi, 36(3), 1-15.

Deichmann, U. (2015). Chromatin: Its history, current research, and the seminal researchers and their philosophy. Perspectives in Biology and Medicine, 58(2), 143-164. 
Dekker, J., et al. (2013). Exploring the three-dimensional organization of genomes: Interpreting chromatin interaction data. Nature Reviews Genetics, 14(6), 390-403.

Dennett, D. (1993). Review of the embodied mind. American Journal of Psychology, 106, 121-122.

Di Paolo, E. (2018). The enactive conception of life. In A. Newen, L. De Bruin, \& S. Gallagher (Eds.), The Oxford handbook of $4 E$ cognition. Oxford: Oxford University Press.

Dias, B. G., \& Ressler, K. J. (2014). Parental olfactory experience influences behaviour and neural structure in subsequent generations. Nature Neuroscience, 17, 89-96.

Fagiolini, M., Jensen, C. L., \& Champagne, F. A. (2009). Epigenetic influences on brain development and plasticity. Current Opinion in Neurobiology, 19, 207-212.

Ferrari, P. F., Tramacere, A., Simpson, E. A., \& Iriki, A. (2013). Mirror neurons through the lens of epigenetics. Trends in Cognitive Sciences, 17(9), 450-457.

Frost, S. The attentive body: How the indexicality of epigenetic processes enriches our understanding of embodied subjectivity. Body \& Society, December issue, 26(4). (in press).

Gabriele, M., Tobon, A., D'Agostino, G., et al. (2018). The chromatin basis of neurodevelopmental disorders: Rethinking dysfunction along the molecular and temporal axes. Progress in NeuroPsychopharmacology and Biological Psychiatry, 84(Pt B), 306-327.

Gallagher, S. (2005). How the body shapes the mind. Oxford: Oxford University Press.

Gallagher, S. (2017). Enactivist interventions. Oxford: Oxford University Press.

Gapp, K., Jawaid, A., Sarkies, P., Bohacek, J., Pelczar, P., Prados, J., et al. (2014). Implication of sperm RNAs in transgenerational inheritance of the effects of early trauma in mice. Nature Neuroscience, 17(5), 667.

Ginsburg, H., \& Jablonka, E. (2018). The evolution of the sensitive soul. Cambridge, MA: MIT Press.

Godden, D. R., \& Baddeley, A. D. (1975). Context-dependent memory in two natural environments: On land and underwater. British Journal of Psychology, 66, 325-331.

Godfrey-Smith, P. (1998). Complexity and the function of mind in nature. Cambridge: Cambridge University Press.

Godfrey-Smith, P. (2017). Complexity revisited. Biology and Philosophy, 32(3), 467-479.

Griffiths, P. E., \& Neumann-Held, E. M. (1999). The many faces of the gene. Bioscience, 49, 656-662.

Griffiths, P., \& Stotz, K. (2000). How the mind grows: A developmental perspective on the biology of cognition. Synthese, 122(1-2), 29-51.

Griffiths, P., \& Stotz, K. (2013). Genetics and philosophy. Cambridge: Cambridge University Press.

Guan, Z., Giustetto, M., Lomvardas, S., Kim, J.-H., Miniaci, M. C., Schwartz, J. H., et al. (2002). Integration of long-term-memory-related synaptic plasticity involves bidirectional regulation of gene expression and chromatin structure. Cell, 111(4), 483-493.

Gudding, G. (1996). The phenotype/genotype distinction and the disappearance of the body. Journal of the History of Ideas, 57(3), 525-545.

Hallgrímsson, B., \& Hall, B. (Eds.). (2011). Epigenetics: Linking genotype and phenotype in development and evolution. Berkeley: University of California Press.

Heard, E., \& Martienssen, R. (2014). Transgenerational epigenetic inheritance: Myths and mechanisms. Cell, 157(1), 95-109.

Heersmink, R. (2017). The narrative self, distributed memory, and evocative objects. Philosophical Studies, 175(8), 1829-1849. https://doi.org/10.1007/s11098-017-0935-0.

Hoel, A. S., \& Carusi, A. (2018). Merleau-ponty and the measuring body. Theory, Culture \& Society, 35(1), 45-70.

Hutto, D. D., \& Myin, E. (2013). Radicalizing enactivism: Basic minds without content. Cambridge, MA: MIT Press.

Hutto, D., Myin, E., Peeters, A., \& Zahnooun, F. (2018). The cognitive basis of computation: Putting computation in its place. In M. Sprevak \& M. Colombo (Eds.), The Routledge handbook of the computational mind. London: Routledge.

Jablonka, E. (2013). Epigenetic inheritance and plasticity: The responsive germline. Progress in Biophysics and Molecular Biology, 111(2-3), 99-107.

Jablonka, E. (2017). The evolutionary implications of epigenetic inheritance. Interface Focus, 7(5), 20160135.

Jablonka, E., \& Lamb, M. (2014). Evolution in four dimensions (2nd ed.). Cambridge: MIT Press.

Jeppesen, P. (1997). Histone acetylation: A possible mechanism for the inheritance of cell memory at mitosis. BioEssays, 19(1), 67-74.

Kay, L. (2000). Who wrote the book of life?. Stanford: Stanford University Press. 
Keijzer, F. (2013). The Sphex story: How the cognitive sciences kept repeating an old and questionable anecdote. Philosophical Psychology, 26(4), 502-519. https://doi.org/10.1080/09515089.2012.69017 7.

Keller, E. F. (2014). From gene action to reactive genomes. Journal of Physiology, 592(11), 2423-2429.

Kim, S., \& Kaang, B.-K. (2017). Epigenetic regulation and chromatin remodeling in learning and memory. Experimental \& Molecular Medicine, 49(1), e281.

Kiverstein, J. (2012). The meaning of embodiment. Topics in Cognitive Science, 4(4), 740-758.

Kucharski, R., et al. (2008). Nutritional control of reproductive status in honey bees via DNA methylation. Science, 319, 1827-1830.

Laland, Kevin N., et al. (2015). The extended evolutionary synthesis: Its structure, assumptions and predictions. Proceedings of the Royal Society B: Biological Sciences, 282, 1813.

Landecker, H. (2016). The social as signal in the body of chromatin. In M. Meloni, S. Williams, \& P. Martin (Eds.), Biosocial matters: Rethinking sociology-biology relations in the twenty-first century. Oxford: Wiley.

Landecker, H., \& Panofsky, A. (2013). From social structure to gene regulation, and back: A critical introduction to environmental epigenetics for sociology. Annual Review of Sociology, 39, 333-357.

Lappé, M., \& Landecker, H. (2015). How the genome got a lifespan. New Genetics and Society, 34(2), 152-176.

Liu, D., Diorio, J., Tannenbaum, B., Caldji, C., Francis, D., Freedman, A., Sharma, S., Pearson, D., Plotsky, P. M., \& Meaney, M. J. (1997). Maternal care, hippocampal glucocorticoid receptors, and hypothalamicpituitary-adrenal responses to stress. Science, 277(5332), 1659.

Lutz, P., \& Turecki, G. (2014). DNA methylation and childhood maltreatment: From animal models to human studies. Neuroscience, 264, 142-156.

Lyon, P. (2006). The biogenic approach to cognition. Cognitive Processing, 7(1), 11-29.

Lyon, P. (2017). Environmental complexity, adaptability and bacterial cognition: Godfrey-Smith's hypothesis under the microscope. Biology and Philosophy, 32(3), 443-465.

Margueron, R., \& Reinberg, D. (2010). Chromatin structure and the inheritance of epigenetic information. Nature Reviews Genetics, 11(4), 285-296.

Maturana, H. R., \& Varela, F. J. (1987). The tree of knowledge. Boston: Shambhala.

Meacham, D., \& Papageorgiou, A. (2007). Transgenerational epigenetics, or the spectral history of the flesh: A merleau-pontian approach to epigenetics. Chiasmi International, 9, 65-93.

Meloni, M. (2016). Political biology. Science and social values in human heredity from eugenics to epigenetics. New York: Palgrave/Springer.

Meloni, M. (2018). A postgenomic body: Histories, genealogy, politics. Body \& Society, 24(3), 3-38.

Meloni, M. (2019). Impressionable biologies. From the archaeology of plasticity to the sociology of epigenetics. New York: Routledge.

Menary, R. (2018). Cognitive integration. In A. Newen, L. De Bruin, \& S. Gallagher (Eds.), The Oxford handbook of 4 E cognition. Oxford: Oxford University Press.

Merleau-Ponty, M. (2003). Nature: Course notes. Trans. R. Vallier. Evanston, IL: Northwestern University Press.

Merleau-Ponty, M. (2012). Phenomenology of perception. Trans. D. Landes. New York, NY: Routledge.

Moore, D. (2015). The developing genome: An introduction to behavioural epigenetics. Oxford: Oxford University Press.

Morris, D. (2010). Empirical and phenomenological studies of embodied cognition. In D. Schmicking \& S. Gallagher (Eds.), The handbook of embodied cognition. New York, NY: Springer.

Moss, L. (2003). What genes can't do. Cambridge, MA: MIT Press.

Mychasiuk, R., \& Metz, G. (2016). Epigenetic and gene expression changes in the adolescent brain: What have we learned from animal models? Neuroscience and Biobehavioral Reviews, 70, 189-197.

Newen, A., De Bruin, L., \& Gallagher, S. (2018). 4E cognition: Historical roots, key concepts, and central issues. In A. Newen, L. De Bruin, \& S. Gallagher (Eds.), The Oxford handbook of 4E cognition. Oxford: Oxford University Press.

Nicol-Benoit, F., Le Goff, P., \& Denis, M. (2013). Drawing a Waddington landscape to capture dynamic epigenetics. Biology of the Cell, 105(12), 576-584.

Noë, A. (2004). Action in perception. Cambridge, MA: MIT Press.

Odling-Smee, F., Laland, K., \& Feldman, M. (2003). Niche construction: The neglected process in evolution. Princeton, NJ: Princeton University Press.

Oyama, S. (2011). Life in mind. Journal of Consciousness Studies, 18(5-6), 83-93. 
Oyama, S., Griffiths, P., \& Gray, R. (Eds.). (2001). Cycles of contingency: Developmental systems and evolution. Cambridge, MA: MIT Press.

Painter, R., Osmond, C., Gluckman, P., et al. (2008). Transgenerational effects of prenatal exposure to the Dutch famine on neonatal adiposity and health in later life. BJOG: An International Journal of Obstetrics and Gynaecology, 115, 1243-1249.

Pal, S., \& Tyler, J. K. (2016). Epigenetics and aging. Science Advances, 2(7), e1600584.

Peeters, A., \& Segundo-Ortin, M. (2019). Misplacing memories? An enactive approach to the virtual memory palace. Consciousness and Cognition, 76, 102834.

Piersma, T., \& van Gils, J. (2011). The flexible phenotype: A body-centred integration of ecology, physiology, and behaviour. Oxford, NY: Oxford University Press.

Pinel, C., Prainsack, B., \& McKevitt, C. (2018). Markers as mediators: A review and synthesis of epigenetics literature. BioSocieties, 13(1), 276-303.

Portela, A., \& Esteller, M. (2010). Epigenetic modifications and human disease. Nature Biotechnology, $28(10), 1057$.

Posner, R., Toker, I. A., Antonova, O., Star, E., Anava, S., Azmon, E., et al. (2019). Neuronal small RNAs control behaviour transgenerationally. Cell, 177(7), 1814-1826.

Post, R. M. (2016). Epigenetic basis of sensitization to stress, affective episodes, and stimulants: Implications for illness progression and prevention. Bipolar Disorders, 18(4), 315-324.

Ravetz, J. (1999). What is post-normal science? Futures, 31, 647-653.

Reynolds, J. (2018). Phenomenology, naturalism and science: A hybrid and heretical proposal. London: Routledge.

Rheinberger, H.-J., \& Müller-Wille, S. (2017). The gene: From genetics to postgenomic. Chicago: University of Chicago Press.

Richards, E. (2006). Inherited epigenetic variation: Revisiting soft inheritance. Nature Reviews Genetics, 7, 395-401.

Richardson, S., \& Stevens, H. (Eds.). (2015). Postgenomics: Perspectives on biology after the genome. Durham, NC: Duke University Press.

Riskin, J. (2016). The restless clock: A history of the centuries-long argument over what makes living things tick. Chicago: University of Chicago Press.

Shapiro, L. (2012). Reductionism, embodiment, and the generality of psychology. In M. Schouten \& H. L. de Jong (Eds.), The matters of the mind. New York: Wiley-Blackwell.

Shapiro, L. (2019). Flesh matters: The body in cognition. Mind and Language, 34, 3-20. https://doi.org/1 $0.1111 /$ mila. 12203 .

Sheets-Johnstone, M. (2011). Embodied minds or mindful bodies? A question of fundamental, inherently inter-related aspects of animation. Subjectivity, 4(4), 451-466.

Stallins, J. A., Law, D., Strosberg, S., \& Rossi, J. (2018). Geography and postgenomics: How space and place are the new DNA. GeoJournal, 83(1), 153-168.

Steffen, P. A., \& Ringrose, L. (2014). What are memories made of? How Polycomb and Trithorax proteins mediate epigenetic memory. Nature Reviews Molecular Cell Biology, 15(5), 340-356.

Sterelny, K. (1990). The representational theory of mind. Oxford: Blackwell.

Stotz, K. (2006). With genes like that, who needs an environment? Postgenomics' argument for the ontogeny of information. Philosophy of Science, 73(5), 905-917.

Stotz, K. (2008). The ingredients for a postgenomic synthesis of nature and nurture. Philosophical Psychology, 21(3), 359-381.

Sutton, J., \& Williamson, K. (2014). Embodied remembering. In L. A. Shapiro (Ed.), The Routledge handbook of embodied cognition (pp. 315-325). London: Routledge.

Tark-Dame, M., van Driel, R., \& Heermann, D. (2011). Chromatin folding-From biology to polymer models and back. Journal of Cell Science, 124(6), 839-845.

Thompson, E. (2007). Mind in life. Cambridge, MA: Harvard UP.

Thompson, E., \& Stapleton, M. (2009). Making sense of sense-making: Reflections on enactive and extended mind theories. Topoi, 28(1), 23-30.

Todes, S. (2001). Body and world. Cambridge, MA: MIT Press.

Van Speybroeck, L. (2002). From epigenesis to epigenetics: The case of $\mathrm{CH}$ Waddington. Annals of the New York Academy of Sciences, 981(1), 61-81.

Varela, F. (1996). Neurophenomenology: A methodological remedy for the hard problem. Journal of Consciousness Studies, 3(4), 330-349. 
Waterland, R., \& Jirtle, R. (2003). Transposable elements: Targets for early nutritional effects on epigenetic gene regulation. Molecular Cell Biology, 23, 5293-5300.

West-Eberhard, M. (2003). Developmental plasticity and evolution. Oxford: Oxford University Press.

Wheeler, M. (2005). Reconstructing the cognitive world. Cambridge, MA: MIT Press.

Wheeler, M. (2007). Traits, genes and coding. In M. Matthen, C. Stephens, D. M. Gabbay, P. Thagard, \& J. Woods (Eds.), Philosophy of biology handbook of the philosophy of science (pp. 369-399). Amsterdam: Elsevier.

Wheeler, M., \& Clark, A. (2008). Culture, embodiment and genes: Unravelling the triple helix. Philosophical Transactions of the Royal Society B, 363, 3563-3575.

Williams, J. M., \& Kyrke-Smith, M. (2018). Bridging synaptic and epigenetic maintenance mechanisms of the engram. Frontiers in Molecular Neuroscience, 11, 369.

Zovkic, I. B., Guzman-Karlsson, M. C., \& Sweatt, J. D. (2013). Epigenetic regulation of memory formation and maintenance. Learning \& Memory, 20(2), 61-74.

Publisher's Note Springer Nature remains neutral with regard to jurisdictional claims in published maps and institutional affiliations. 